\title{
PREVALÊNCIA DE IMAGENS CORONÁRIAS RADIOLÚCIDAS EM DENTES NÃO IRROMPIDOS EM CRIANÇAS NO CURSO DE ODONTOLOGIA DA UFPR
}

Thaís Santiago GOULARTE, Ângela FERNANDES

Ao avaliar uma radiografia odontológica o cirurgião-dentista pode se deparar com vários achados. Entre esses, podem estar imagens radiolúcidas coronárias em dentes não irrompidos. Essas imagens representam hipoplasias dentinárias. São assintomáticas e resultam de desvios de normalidade no desenvolvimento da dentina. Quando não diagnosticadas e tratadas podem evoluir causando comprometimento dentário severo ou até mesmo a perda do dente comprometido. O objetivo deste estudo foi estimar a prevalência dessas anomalias por meio de panorâmicas de crianças. Foram avaliadas 292 radiografias panorâmicas obtidas dos prontuários da disciplina de Odontopediatria da UFPR entre 2003 a 2008. A idade da amostra variou de 4 a 10 anos. As radiografias foram avaliadas em sala escura, sobre negatoscópio e os dados foram registrados. Avaliou-se 3757 dentes permanentes não irrompidos, dos quais sete $(0,18 \%)$ dentes apresentaram imagens coronárias radiolúcidas. Destes, dois dentes afetados eram segundos pré-molares inferiores, um primeiro pré-molar inferior, três primeiros molares inferiores e um segundo molar superior. Apesar da baixa prevalência de imagens coronárias radiolúcidas em dentes não irrompidos observadas na amostra estudada, a interpretação radiográfica minuciosa deve ser ressaltada, pois essas imagens podem passar despercebidas. É necessário diagnóstico precoce das mesmas para se adotar medidas corretas de tratamento.

Palavras-chave: Radiografia Panorâmica; Ragiografia Dentária; Diagnóstico 